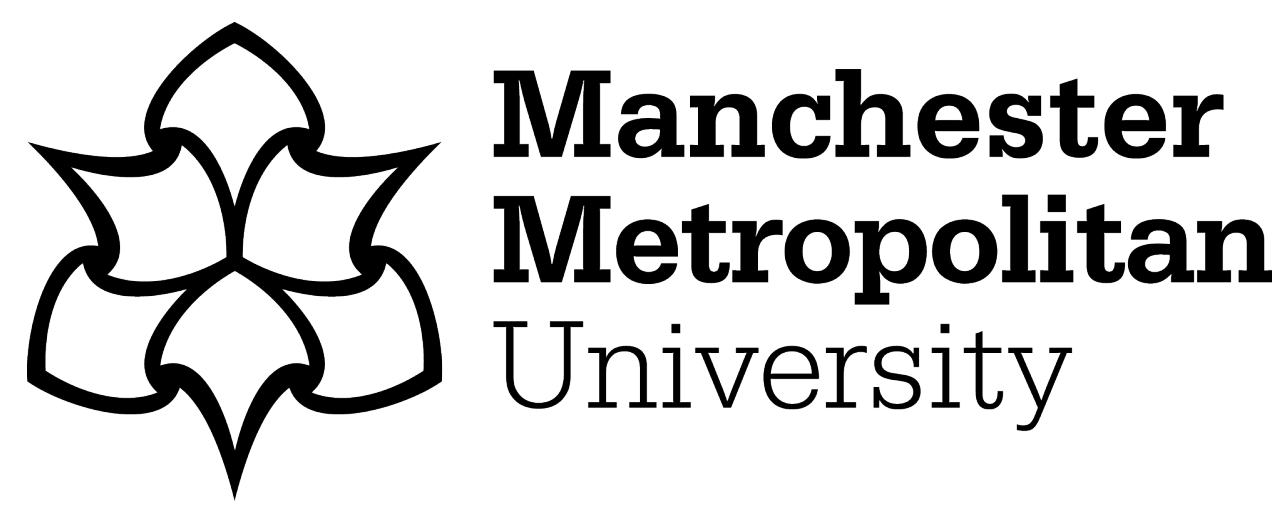

Stevenson, Andrew, Oldfield, Jeremy and Ortiz, Emily (2019) Streets of resilience: exploring the role of educational outreach projects with street connected young people in Guatemala City. Journal of Community \& Applied Social Psychology, 29 (3). pp. 238-253. ISSN 1052-9284

Downloaded from: https://e-space.mmu.ac.uk/622497/

Version: Accepted Version

Publisher: Wiley

DOI: https://doi.org/10.1002/casp.2397

Please cite the published version 


\title{
Streets of Resilience: exploring the role of educational outreach projects amongst street connected children in Guatemala City
}

\author{
Stevenson, Oldfield, \& Ortiz (2019). Image and word on the street: a reflexive, \\ phased approach to combining participatory visual methods and qualitative \\ interviews to explore resilience with street connected young people in Guatemala \\ City. Qualitative Research in Psychology DOI 10.1080/14780887.2018.1557769.
}

\begin{abstract}
We explored resilience amongst Street Connected Young People (SCYP) in Guatemala City in relation to two community based educational outreach projects who work with at risk young people. We investigated (i) how these projects adapt and constructed meaningful spaces of safety and protection for SCYP, and (ii) how their interactions with the families of SCYP impact on wellbeing amongst SCYP. We focused on resilience-building elements and practices, rather than on the dangers of street connectedness. Using ethnographic interviews, participatory photography and image elicitation, we worked with eight young people and four adult project volunteers. Our research yielded evidence that dwellings, market stalls, buildings used for religious purposes are being adapted as spaces of aspiration and opportunity to promote resilience. We found evidence of rifts between education projects and parents, and evidence for strategies for repairing these rifts. Our findings highlight the importance of community educational organisations in Guatemala City, and have implications for their practice.
\end{abstract}

Keywords: resilience; Guatemala; education, voluntary, place, streetconnected, ethnography, photography

\section{Introduction}

Resilience involves psychological, social, cultural, and physical resources sustaining wellbeing in the face of risk, hardship or adversity (Masten, 2014). Those with better than expected wellbeing or educational outcomes under these circumstances are regarded as demonstrating resilience. From an ecological perspective, resilience is regarded as a process rather than as a psychological trait (Masten, 2014, Ungar, 2011). Resilience occurs where family, social and community agencies support individuals towards increased wellbeing (Duff, 2008, Lounsbury \& Mitchell, 2009). In this paper we argue that ecological approaches to resilience related to the production of meaningful, flexible, spaces (Lefebvre, 1971, Soja, 1996). Using literature on resilience and spatiality, we explore the work of two community based educational outreach projects in Guatemala City in aiding SCYP to overcome risks faced when living and working on the street. We explore (i) how these projects adapt and construct meaningful spaces of safety and protection for SCYP, (ii) how their interactions with the families of SCYP impact on SCYP's well-being. We begin by outlining the challenges of youth street-connectedness.

SCYP may be abandoned, living with their homeless family, or working on the street (Pluck, 2015). Associations between homelessness and street-connectedness amongst young people with health related and behavioural risk are well-documented (Tobin \& 
Murphy, 2013, Masten et al, 2014). Adverse life experiences occur more regularly amongst children without regular housing, compared to those from housed backgrounds (Masten et al, 2014). Street-connectedness and residential instability disrupt academic achievement (National Research Council, 2010). Researchers have identified risks that homeless young people face, and the protective factors that educators and community agencies can utilise to address them (Masten, 2011). Adverse experiences include low educational achievement, friendship instability and negative life expectations (Evans \& Kim, 2012, Masten et al, 2014). The identification of residential instability as a risk factor highlights the value of permanent homes for advancing educational achievement. Projects such as the Harlem and Minneapolis Northside Achievement Zones (Tough, 2009, Masten et al, 2014) demonstrate the link between secure housing, educational achievement and aspiration. This U.S. based work highlights a need for greater exploration of homelessness, risk and protective factors across cultures (Masten et al, 2014) where chronic poverty prevails and homelessness is acute (Le Mèner \& Oppenchaim, 2012; Shinn \& Greer, 2011) The present paper broadens the scope of research into street-connectedness by exploring the role of community outreach projects in Guatemala City.

Guatemala's population is approximately $16,673,000$, with $60 \%$ living in poverty (Hernandez et al, 2017). Over $30 \%$ of Guatemalan young people fail first grade (6 years) at school. Enrolment for middle school (12-14 years) is commonly under $40 \%$, and only half of 8-year olds achieve national reading and mathematics standards (U.S. Aid, 2016). Over 2 million 15-24-year olds in Guatemala lack basic skills necessary for employment (U.S. Aid, 2016). Guatemala City has an estimated population of 2.74 million people (World Population Review, 2017). UNICEF (2016) reports that approximately $26 \%$ of Guatemalan children sell produce and recycle waste in ' $\mathrm{La}$ Terminal', Guatemala City, where our primary research was conducted.

SCYP are often found within large urban settings with discrepancies between rich and poor (Pluck, 2015) and high risk of negative life experiences (Thomas de Benitez, 2011). Researching 972 child streetworkers in Guatemala and four other Latin American cities, Pinzón-Rondón et al. (2006) reported 18\% to be homeless, and 48\% working in the street, unsupervised. Latin America's urban youth face a "continual state of radical insecurity" (Thrift, 2005, p. 133). Few studies focus on strategies for improving wellbeing (Pluck, 2015), yet survival strategies amongst SCYP reveal motives for street connectedness to include friendship, making a living, and personal development (Pacherres et al, 2003). Average intellect amongst SCYP is below the population mean (Pluck 2015), yet flourishing task-specific, on-the-job mathematical abilities have been observed (Greiffenhagen \& Sharrock, 2008). Moreover, when Peruvian SCYP were compared with a poor, non-SCYP control group, no cognitive differences emerged. Indeed, on one measure of divergent thinking, the former excelled (Dahlman et al., 2013). Such findings suggest that well-being and personal development amongst SCYP can rally where circumstances allow. We now review a theoretical concept that helps us understand how SCYP might overcome risk.

Resilience is the capacity of individuals to navigate their way to the psychological, social, cultural, and physical resources that sustain their wellbeing

(Ungar, 2011:10) 
Resilience relates to developing wellbeing in the face of risk (Ungar, 2012). From an ecological perspective resilience is regarded as a process wherein protective factors operate across ecological levels (individual, school, community), moderating risk, increasing wellbeing (Masten, 2014, Ungar, 2015). Much psychological literature adopts individualised approaches to resilience (Friborg, 2010, Ungar et al, 2013). For example, clinical studies of neurophysiology (Romeo \& McEwen, 2006) and genetic profiling (Bartels \& Hudziak, 2007) identify biological factors predisposing positive development in adverse settings, with certain environmental factors present (Ungar, 2011). This approach frames resilience as a deficit, residing in the individual. We eschew the 'vulnerable individual' model, preferring to emphasising how individuals, families, peers and communities pool psychological and physical resources to enhance wellbeing (Ungar, 2011).

In Guatemala many young people face risks that are rooted in inequality, corruption and violence (Castañada \& del Pilar Grazioso, 2017). Social and community agencies seek to manage risk amidst adversity (Duff, 2008, Lounsbury \& Mitchell, 2009). Arguably, the greater the inequality and adversity, the greater the need for community interventions (Masten, 2014). To counter individualising approaches, a mesosystemic orientation (Ungar, 2013) frames resilience as an interaction between families, schools and communities, fostering supportive, enabling environments (Lee, 2006). Enabling environments can be created by religious groups (Donnon \& Hammond, 2007), peers (Mikami \& Hinshaw, 2006) and schools (Theron \& Engelbrecht, 2012). Wellbeing is associated with such groups committing time and communicating with one another. Conversely, where conflicts emerge between values and aspirations of these agencies, development stalls (Liebel, 2004).

Using a social ecological approach, we explore resilience amongst SCYP in Guatemala City in relation to two community educational outreach projects, from a community psychology perspective (Levine et al, 2005). Rooted in Latin American indigenous psychology (Sloan, 2002), community psychology endorses research that collaborates with community representatives (Kagan et al, 2011). The "habits of solidarity" (Amin, 2006, p. 1016) engendered by these projects bring together friends, families and strangers in spaces (Joanou, 2014) that are infused with meaning and positive affect. Such meaningful spaces, made from personal networks, buildings and resources (Duff, 2008), aspire to foster wellbeing. To help understand how communities construct enabling environments where material resources are limited, we turn to the concept of thirdspace (Soja, 1996).

Thirdspace critiques an over-separation, in writings on spatiality, of lived space from imagined, internally represented, 'second-space' (Lefebvre, 1991). Thirdspace combines "the real and the imagined" (Soja, 1996, p10). It is a malleable domain that is at once lived, perceived and practised into being. Joanou (2014) identifies locations in Lima, Peru, adapted by voluntary educational projects working with SCYP, that have become meaningful places of possibility. Street spaces used by outreach projects were spaces where alternative identities were enacted. They were temporarily adapted by children and educators (Matthews, Limb, and Taylor 2000). As part of a growing Latin American literature on spatiality and well-being (Burrell, 2010, Joanou, 2014, Groot \& Hodgetts, 2015, Goldstein, 2016), we use thirdspace to explore the work of two Guatemalan community outreach organisations in relation to their promotion of resilience with SCYPs. We ask how they construct and adapt spaces of resilience, and 
how their interactions with SCYP impact wellbeing.

\section{Method}

Our research was carried out by a three-person team, over two phases of fieldwork in Guatemala City. The lead (Spanish speaking) researcher conducted phase one of the study whilst volunteering for two educational outreach projects during a 4-week visit to Guatemala (from the UK). For phase 2, a second (Guatemalan) and third (UK-based) researcher worked with the lead researcher in Guatemala over a 4-week period, in collaboration with outreach project leaders and volunteers. During phase one the lead researcher volunteered with two outreach projects, Puertas de Esperanza and Resplandece, two or three days weekly, helping with language, art and numeracy classes, with mobile classes for SCYP and their parents at a site called 'La Terminal' (see below). Contact was also made with the second (Guatemalan) researcher, who also volunteered. During this phase, project leaders agreed to act as gatekeepers. Access to research sites (see below) was negotiated, as were research questions that would be interesting for researchers and project leaders. During phase two (six months later) the research team worked closely with the outreach projects, helping with classes whilst collecting data. This work took place across three research sites in Guatemala City over four weeks.

Research site one; a residential house, used by the volunteer-run project, Puertas de Esperanza. This residence of two project leaders has a communal learning room, kitchen and sanitary facilities. Site two, a place of worship housing another outreach project, Resplandece, offers computer terminals, classroom and sanitary facilities. Volunteers collect SCYP twice weekly and drive them to class by minibus, often bringing food for SCYP. Site three, La Terminal, is an extensive public space incorporating markets, bus station, dump and housing blocks, where hundreds of SCYP and their families live and work. Volunteers assemble SCYP twice weekly at La Terminal and set up learning areas in semi-undercover corridors.

Twelve participants (see Table 1) were recruited under guidance from gatekeepers, during regular sessions of the two outreach projects. Both projects provide classes for SCYP who do not attend mainstream schooling. Sampling criteria were that all SCYP participants should be regular attendees of one or other project. For adults, criteria were that participants should be regularly involved project leaders of volunteers.

Table 1. Participants (pseudonymous)

\begin{tabular}{|l|l|}
\hline Luis & Outreach project leader \\
\hline Julia & Outreach project leader \\
\hline Anna & Outreach project leader \\
\hline Ignacio & Outreach project volunteer \\
\hline Jo & SCYP, male, 11 \\
\hline Miguel & SCYP, male, 14 \\
\hline Wilma & SCYP, female, 15 \\
\hline Felipe & SCYP, male, 11 \\
\hline Favi & SCYP, female, 13 \\
\hline
\end{tabular}




\begin{tabular}{|l|l|}
\hline Nadia & SCYP, female, 14 \\
\hline Carl & SCYP, male, 13 \\
\hline Jan & SCYP, female, 12 \\
\hline
\end{tabular}

Fieldwork was conducted according to ethical standards set down by our university, requiring us to gain additional consent from participants who appeared in photographic images. Informed consent for participation of all SCYP was obtained from parents. All names have been changed. During interviews, any issues raised that were regarded as matters for concern were shared with gatekeepers. All interviews were conducted in public spaces, or within the two voluntary educational outreach projects.

Data collection was carried out using ethnographic interviewing (Spradley, 1979, Pink, 2009), participatory photography (Barker, 2009, Gallagher et al, 2010, Power et al, 2014) and image-elicitation (Pauwels, 2015). Ethnographic interviewing engages with overlapping experiences of interviewers and interviewers, in relation to physical emplacement of the fieldworker and the sensory nature of the work. Previously, ethnographic interviewing has been used in relation to practices such as eating (Pink, 2009) and walking (Moles, 2008, Stevenson, 2014). Interviews took place in locations where participants were routinely familiar. They were often conducted on-the-go (Stevenson, 2014), and always in Spanish. Example interview questions included; (i) 'Can you show me something that you enjoy doing here?'; (ii) 'If ever you had to leave this place, what would you miss?

Alongside interviews, SCYP were asked to make photographs of places where they live, work and learn. Participants were invited to lead go-along sessions, to select spaces for interviews, and photographic subjects. This method is participatory in that knowledge is being selected and created with participants as equal partners (Pauwels, 2014). It yields tangible, visual outputs which are owned by and shared between participants.

Participatory photography facilitated high engagement with SCYP through the learning of a novel skill (Pauwels, 2015). Photographs were made using disposable cameras and a smartphone, provided by the researchers. All photographs were returned to participants in hard copy at the end of the study. Our use of image elicitation aligns with work by others who have used innovative visual methods to deepen participant engagement (Karabanow, 2013, Mizen \& Ofosu-Kusi, 2013). Images are also used as interview elicitation tools to illustrate themes that have been identified from interview transcripts, but we are not explicitly using images as data for analysis. We acknowledge that subsequent work might employ a phenomenological analysis of images (Papaloukas et al, 2017).

Following translation, interview transcripts were analysed thematically, iteratively assigning, comparing, and revising codes (Braun \& Clark, 2006, Langdridge et al, 2013). Emerging themes and sub-themes were influenced by the existing literature, and grounded in the properties of the data, incorporating inductive and deductive aspects (Langdridge et al, 2013). To complement explicit these thematic categories, an interpretive thematic analytic approach (Jackson \& Mazzei, 2012) was used to extract further implicit content from the interview transcripts. Following thematic analysis, identification of images to illustrate themes was undertaken (Gallagher et al, 2010). Images used were produced by participants and are presented here alongside quotes. 


\section{Findings}

Our findings centre around the role of educational outreach projects in constructing meaningful spaces of belonging for young people, and on the strategies used by these projects to tackle challenges and rifts faced by SCYP. Findings cluster into three broad themes relating to distinct aspects of participants' experiences; (i) spaces, (ii) rifts, (iii) repairs. Analysis further yielded sub-themes (Table 2). Interpretive thematic analyses complement these categories (Jackson \& Mazzei, 2012).

Table 2. Themes and subthemes

\begin{tabular}{|l|l|}
\hline Theme & Subtheme \\
\hline Spaces & $\begin{array}{l}\text { Safe, resilient spaces } \\
\text { Fluid, resilient spaces }\end{array}$ \\
\hline Rifts & $\begin{array}{l}\text { Agencies in conflict } \\
\text { Selective domains of resilience }\end{array}$ \\
\hline Repairs & $\begin{array}{l}\text { Engaging the whole person } \\
\text { Supporting families } \\
\text { Aspiration }\end{array}$ \\
\hline
\end{tabular}

\section{Spaces}

There was a distinct spatial element to the work of the voluntary outreach projects. Both Puertas de Esperanza and Resplandece utilise space in ways that extend a sense of belongingness and resilience for young people into their immediate environments. Two subthemes emerged in relation to space.

\section{Safe, resilient spaces}

A key aspect of the work of educational outreach projects is their potential for protecting SCYP by offering spatial respite from La Terminal.

For us it is pretty evident that they don't really study in their house because they are busy doing something else or working in La Terminal, and the time they really use to study is only the time they come here. (Julia, project leader, line 8)

Recently Nadia (SCYP) was telling me, 'I don't want to be in The Terminal anymore, can you help me to see if I can do something else?' (Luis, project leader, line 17)

The protective element of spaces provided by Puertas de Esperanza was illustrated using participatory photography. Miguel was asked what he would miss most if he could not attend. Walking us through the house, Miguel took us to the living room, photographed it, and said simply said 'the class' (see figure 1). Later, when interviewed again, he echoed Nadia's words, saying

I don't want to go to La Terminal anymore. They make you do bad things. (Line 14)

Figure 1. Puertas de Esperanza classes take place in a living room, with permission of participant photographer. 
At a more interpretive analytic level (Jackson \& Mazzei, 2012), in relation to the value of outreach projects as alternate, safe spaces, we can see how Nadia and Miguel implicitly refer to the dangers of La Terminal in stating their keenness to do 'something else' (Nadia). Whilst the dangers of La Terminal are perhaps only obliquely referred to by Miguel in utterances such as 'they make you do bad things', it is often present absence (Jackson \& Mazzei, 2012) of detail that signifies meaning, in this case of the risks being posed at La Terminal.

Puertas de Esperanza and Resplandece offer spatial sanctuary for facilitating wellbeing. They are protective partly because they are situated in safe spaces, away from La Terminal. These learning spaces exemplify enabling environments (Duff, 2008). By providing safe spaces outreach projects act as ecological mediators of resilience (Unger, 2012). As "assemblages of personal networks and environmental characteristics which together work to enhance or impede the experience of health and wellbeing" (2008: 204), enabling environments highlight resilience as a relational, emplaced phenomenon that resides beyond the individual.

To complement our interpretations of textual utterances, in using go-along photography to demonstrate belongingness, we can see how participants such as Miguel (and Wilma, below) use their agency to walk and show us how identifying with meaningful places can endow belongingness through regular involvement, attendance and practice. This visual, go-along method for showing meaningful space resonates with the work of other authors who have linked self-worth and place-making through the use of visual methods (Groot \& Hodgetts, 2015, Mizen \& Ofosu-Kusi, 2012, Padgett et al, 2013). In using similar methods, we contest that the work of voluntary, community-based education outreach projects in Guatemala City constructs enabling environments that are capable of affording breathing spaces for learning.

\section{Fluid, resilient spaces}

Besides offering sanctuary, another spatial feature of the work of educational outreach for promoting ecologies of belongingness is the fluid, transient nature of these spaces.

The place where we're having the classes, it's the living room of the house. We are adapting to this space, right? (Luis, outreach project leader, line 30)

The living room is part of the residence of the project leaders, providing bathroom facilities, a kitchen; a place to feel at home. It is adapted twice weekly as a classroom space, where SCYP are brought to learn. The second field site, used by Resplandece, also represents a spatial adaption. Twice weekly, volunteers use a building that was designed for purposes other than teaching.

It's a church building. Three days a week there are church services going on. It's a church building but thankfully they also allow us to use it. (Anna, outreach project leader, line 49)

The third site occupies an outdoor, street-level location at La Terminal. Aisles between accommodation blocks are adapted for learning on a weekly basis. Small chairs and learning resources are set out for SCYP. Using her camera to illustrate (see figure 2), Wilma referred to the mobile, 'pop-up' classes as a welcome addition to life at La Terminal. 
Interviewer: Is there anything here that helps you when you have problems?

Wilma: Studying. I love our teachers very much. They have helped us since we were little girls. (Line 12)

Figure 2. Classes at The Terminal, with permission of participant photographer.

We can further interpret explicit statements and images about adaptive space in relation to an underlying, implicit willingness to infuse space with alternate meanings. Wilma's photograph displays a basic arrangement for schooling that is similar to a description used in another study using participatory photography in relation to educational outreach, in that it shows 'myriad shacks in an extensive network of alleyways and footpaths' (Mizen \& Ofosu-Kusi, 2013, p.15). Yet as she describes the spatial adaptation she has captured photographically, it is enlightening to see how Wilma infuses her snapshot with meaning that transcends the present moment of the image, towards a period that encompasses her lifespan, by saying 'since we were little girls'. Arguably, image elicitation is transformative in that enables SCYP like Wilma (above) to elicit meanings that project into other time frames, such as earlier childhood

Adapted spaces are simultaneously classrooms, houses and places of worship. Those who adapt them create spaces, transform them and endow them with meaning though regular practice (Lefebvre, 1971). These meaningful thirdspaces (Soja, 1996) are real, lived and aspirational. They are spatial adaptations that are meaningful in the here and now. They have accrued meanings over time, and their meanings often go beyond the purpose for which they were originally built. For instance, a church is reimagined as a school. It is perhaps apposite that educational outreach projects utilize spaces that usually are not used as schools. Arguably, the use of adapted spaces is advantageous in that SCYP are able to develop meaningful practices in settings that they do not solely associate with schooling.

\section{Rifts}

Whilst both Puertas de Esperanza and Resplandece demonstrably adapt and construct places of meaning and belonging, during our research we also observed rifts that represented challenges for SCYP. These rifts can be interpreted at the mesosystemic level (Ungar, 2012), as they relate to discord between agencies in the life-worlds of SCYP, reflecting the fragmented nature of certain domains of experience.

\section{Agencies in conflict}

At times outreach volunteers reported educational aims that were not shared by SCYP's families. Obligations to work for money were sometimes prioritised at home. An extreme example of this conflict is explained here.

One of the most horrible stories that I heard from a colleague, was how parents negotiated that their daughter would be sexually abused, because they were drunk and then needed the money. (Ignacio, outreach project leader, line 72)

In relation to mesosystemic rift (Unger, 2012) between families and educators, some parents prefer their children to spend time earning money at La Terminal. Conflict exists between priorities of earning and learning. 
It has a lot to do with the parents. They have the opportunity to change the fate of the children, but they often don't want to let the children stop work. (Ignacio, outreach project volunteer, line 77)

Earlier we framed resilience and wellbeing using an approach that emphasises how families, peers and communities work together across different life domains. At a more interpretive level, using a mesosystems approach, Ungar (2012) stresses the importance of quality communication between agencies such as families, schools and religious communities. Halted development can occur when educators and caregivers communicate irregularly (Nix et al, 2005). Our findings identify conflicts between values and aspirations held by families and educators, especially in relation to paid work. Whilst we acknowledge those who highlight benefits that youngsters reportedly derive from work in the absence of formal education, (Liebel, 2004), we stress important role that outreach projects play in identifying harmful rifts between educational and domestic aspirations.

\section{Selective domains of resilience}

As well as the disconnect between families and educators, we observed a further rift between domains of experience in the life-worlds of SCYP. Resilience was reported as a selective phenomenon. For many SCYP, it was present in some domains, yet absent in others

I think they have a high level of resilience to survival in terms of nutrition, of sleeping in difficult or inappropriate conditions, but I think there is very little or almost no resilience in the affective needs. (Julia, outreach project leader, line 38)

Where poverty, limited access to sanitation and educational opportunity are common, these risks can be tolerated. Yet in terms of risks related to emotional, familial or interpersonal support, coping was less developed.

There is little resilience in the personal affective areas and a lot in terms to do with survival, to a point that they would eat out of the rubbish. (Julia, outreach project leader, line 27)

Our observation of resilience as a selective phenomenon supports those who note the concept's fragmented nature (Keenan et al, 2016), despite the less widely reported view of resilience as an all-or-nothing concept (Chandler \& and Coaffee, 2016). From an ecological perspective we suggest that when a child is adequately protected in some domains, yet not in others, wellbeing can be inconsistent. For example, resilience has previously been observed in school settings, yet absent in the same children at home (Cicchetti \& Toth, 1998, Keenan et al, 2016). The SCYP we interviewed appeared to be well supported in terms of coping with material hardship, poor sanitation and overcrowding. However, there was less affective support, perhaps due to transient familial situations and absent parents. Our findings highlight the relational nature of a concept that is contingent on a need for support networks across various life domains.

\section{Repair}


Having credited the adaptive, spatial elements of the work of Puertas de Esperanza and Resplandece in the face of the fragmented experiences of SCYP, we can also report on the strategies employed by projects for repairing rifts.

\section{Engaging the whole person}

Seeking to build bridges between disconnected domains of experience, project leaders identified a need for support beyond education. Whilst outreach projects are ostensibly educational, diverse risks faced by SCYPs necessitated broader provision.

The educational area is right now the strongest one, in matters of health we've also supported them. We've started to work with therapies with some of the children and also in the spiritual area. (Luis, outreach project leader, line 41)

Outreach projects have a holistic, across domain approach. Many SCYP recognised this. When asked to photograph something enjoyable about an outreach project (see figure 3), Miguel (SCYP) chose the kitchen.

Interviewer: What do you like about this place?

Miguel (SCYP): Here I learn how to cook. If I am older, and I don't want to have a wife, I can cook my own food. (Line 70)

Figure 3. Cooking at Resplandece, with permission of participant photographer.

We can interpret Miguel's kitchen photograph, where he learned to cook, as well as Wilma's photograph of the pop-up class at La Terminal (fig. 2), as signifiers of a connecting up of what might otherwise be disconnected life domains. These images of a kitchen in a temporary school space (fig. 3), and of a temporary school in a street (fig. 4) can be deconstructed as implicit references to the importance of connecting domestic and scholastic domains that combine to cater for the whole person. The diversity and fluidity in provision that is practised by educational projects reflects a tendency to cater for different aspects of SCYPs needs. We acknowledge the idea of resilience as a fragmented phenomenon (Keenan et al, 2016), and note here the wisdom of extending support beyond scholasticism. True, some research correlates resilience with individual personality factors such as neuroticism, extraversion, conscientiousness (Campbell-Sill et al, 2006) and cooperativeness (Ghazinour et al, 2003). However, we argue that engaging across domains (health, nutrition, spirituality) can show that some SCYP are stronger in some areas than in others, and can treat them as whole people.

\section{Supporting families}

In relation to risks posed for SCYP by conflicts of interest between families and education, project leaders identified a need to work closely with parents of SCYP. Since volunteers visit La Terminal each week, there is regular contact with parents.

One of the things that makes them feel more identified, the relationship, with all the family, not only with the young person. (Julia, outreach project leader, line 57)

Extending educational provision to families, outreach projects also teach parents (primarily mothers) basic skills. This forges bonds with families, benefits SCYP and 
enhances inter-agency communication (Ungar, 2012).

We are teaching the Mums. We work with them because they are the core, they are a key person in helping their children with their homework. (Julia, outreach project leader, line 61)

Another way that outreach projects support families is by augmenting duties that parents find it difficult to perform, perhaps because they are unavailable. This is illustrated here by Wilma (SCYP).

E: Does going to that project helps you be different?

Wilma: To behave correctly I think, right?

$\mathrm{E}$ : Does is make you feel safe there?

Wilma: Yes, because they talk to us about good things, they give us advice (line 80)

Felipe (SCYP) highlights the dual supportive roles of his 'profe' (outreach project leader) and his father.

E: Can you say what helps you from this place when you're in trouble

Felipe (SCYP): Calming down

E: Calming down, who helps you calm down?

Felipe: My dad or profe (line 78)

By maintaining regular contact with and offering classes to families, and by supplementing familial duties, stronger bonds between agencies develop. We suggest that besides working with individual youngsters, outreach projects are engaged in valuable mesosystemic engagement (Ungar, 2012). In supporting families directly and directly they seek to reduce conflict between domestic and educational priorities.

\section{Aspiration}

In addition to working with families and supporting SCYP across life domains, another strategy that both outreach projects use to enhance wellbeing is promoting an aspirational ethos. Despite the risks of La Terminal, outreach projects promote project future hope through their work, as reflected in young peoples' responses

E: Why do you like coming here?

Miguel (SCYP): Because I want to be someone in life. (Line 59)

E: What do you learn here?

Wilma (SCYP): To move forward and be someone in life, not being like right now. (Line 91)

In these statements we see how SCYP value the outreach projects beyond the here and now, transcending their present, evident value, into an implicit value whose full realisation remains to be seen in the future (Jackson \& Mazzei, 2012). Central to this aspirational projection into the future is a belief, amongst volunteers, that despite obvious obstacles, circumstances can change.

They can be agents of change for themselves. They can accomplish that level of 
consciousness and the responsibility of saying: I want to be different! I don't want to continue here! (Luis outreach project leader, line 36)

SCYP and volunteers demonstrate the value of a secure base from which to see alternative pathways towards future development. Clearly, a positive, aspirational outlook alone may be insufficient for promoting resilience, yet there is evidence to suggest that amongst young people who feel a sense of belongingness for their learning environment, hope is more likely to develop (Oldfield et al, 2018). In the case of at risk SCYP who participated in this project, the ethos of aspiration coincided with a sense of belongingness and positivity for the outreach projects.

\section{Conclusions and discussion}

We set out to explore resilience amongst SCYP in Guatemala City with two voluntary educational outreach projects. Our work with SCYP, outreach leaders and volunteers yielded three main conclusions.

First, we suggest that resilience cannot merely be regarded as an individual characteristic, but should be understood as emplaced and ecological, extending into the construction of meaningful thirdspaces. Resilience can stem from the adaptation of space by community organisations that foster relationships with other agencies, like families and churches. In Guatemala City, campaigns to reduce risk are being waged in resilient places that are adapted by community networks who have endowed them with meaning. Our study illustrates Soja's (1996) concept of thirdspace, as well as the work of Joanou (2014) in Peru, where spaces of possibility are being carved out by voluntary organisations working with young people. For policymakers in Guatemala, where fulltime schooling is not always viable for SCYP, spatial adaptations, with learning occuring in community settings, could be a valuable strategy (Castañada \& del Pilar Grazioso, 2017).

Secondly, we argue that resilience is a mesosystemic concept (Ungar et al (2013), involving multiple agencies, including educators and families, working together across life domains to promote resilience. Our findings show how outreach agencies forge links with SCYP's families. Arguably, projects such as Puertas de Esperanza and Resplandece, perhaps due to their spatial adaptations, can share some parental, pastoral responsibilities. Thus, we acknowledge the work of volunteers in engaging with SCYP holistically, across several domains. Policymakers might take note of the value of deploying resources to agencies with a holistic ethos.

Thirdly, we conclude is that participatory, mobile methods enable researchers us to draw up closely to a population who are often spoken about, rather than with (Singhal \& Rattine-Flaherty, 2006). There is a well-established methodological tradition using participatory photography and image elicitation with young people in research on resilience and place making (Liborio \& Ungar, 2010; Mizen \& Ofosu-Kusi, 2013). This approach enhances participant ownership of data. Alongside others who have used visual methods with SCYP in Guatemala City (Karabanow, 2013), or who have explored place-making using mobile, photographic methods (Padgett et al, 2013, Groot \& Hodgetts, 2015), we conclude that these methods deepen participant engagement, enhance interview data, and facilitate dissemination. Participatory photography and photo-elicitation introduced variety into our interactions with the SCYP. With cameras in their hands SCYP became engaged and empowered. Resulting images stimulated 
interviews, enabling SCYP to communicate using their own images. The use of visual methods has also enabled dissemination our work in exhibition spaces, beyond academia.

We have showcased important work of voluntary outreach organisations in Guatemala City. We have used concepts such as resilience and spatiality to theorise their contribution. Evidently, Puertas de Esperanza and Resplandece, especially in terms of their engagement with young people, have something to teach psychologists and researchers who work with these populations. For example, a commitment to treating young people holistically, to engaging with them across domains (education, health, spirituality), could integrate more into research on resilience and education. An ethos of engagement at the family level, by working alongside parents, rather than addressing young people as a discrete population, could also be adopted more overtly in psychology.

The literature on homelessness in relation to young people stresses residential instability as a risk for the development of wellbeing (Masten et al, 2014, Tobin \& Murphy, 2013). A key factor mitigating against risk has been evidenced as identification with a longerterm dwelling and the provision of more permanent homes (Tough, 2009). Whilst we cannot claim that outreach projects featuring here providing permanent homes SCYP, our data does show that these projects construct spaces that offer some characteristics of home. Thus, in relation to existing literature on resilience and homelessness, we support the adaptation of fluid, meaningful spaces as a strategy for constructing places of belonging and aspiration (Joanou, 2014).

There is a need for more research into youth homelessness from beyond the US, for findings gathered from populations that may be harder to access, such as in the markets of Guatemala City. Our research stands as a modest response to this need. We accept however that the eradication of homelessness requires deep, structural change. Thus, researchers may be best employed seeking out insights that can lead to practical measures on the ground to promote resilience, such as identifying and enhancing the good practice of educational outreach projects.

There are limitations in conducting research with young people who are irregular in their daily routines. Maintaining reliable contact during fieldwork is challenging. For related reasons, the scope of our study is compromised by the underlying inequality and poverty in Guatemala that we referred to in our introduction. Whilst we have sought to highlight valuable outreach interventions, the challenges faced by SCYP in Guatemala are such that the effect of these projects is likely to be limited. Whilst reflecting on our findings at a follow-up interview, this point was articulated by Anna, project leader at Resplandece

Often, we go down to The Terminal and we think 'How are these kids alive?'. We go down there and these kids are surrounded by danger, and surrounded by horrible things, and they're alive. They get dirty, they're surrounded by germs, they're around dangerous people. There's just something in them that strives for survival but there's only a certain amount we can do. (Line 14)

Finally, we note a third limitation of our research, and a strategy we are employing to address it. We recognise that for community activists and volunteers, academic papers, though informative, lack wide appeal. Hence, as part of our ongoing research, we have 
been able to return to Guatemala, present our findings to these projects, reunite SCYP with hardcopies of their images, and construct a photographic exhibition for families and volunteers. Using these outputs, we also summarised our key findings for project leaders, facilitating discussion relating to their value for future practice. As part of these dialogues we identified a need for future research which focuses on gathering data more directly from parents of SCYP. Outputs from our project have since been adopted by Puertas de Esperanza and Resplandece for promotional use, and in volunteer training. We would like to end here by reiterating the value of presenting academic research findings both in academia, and in forms that impact participants and gatekeepers.

\section{References}

Amin, A. (2006). The good city. Urban Studies, 43, 1009-1023.

Barker, J. (2009). Driven to distraction: Children's experiences of cars. Mobilities, 4, 59-73.

Bernat, F. (2009). Youth resilience: Can schools enhance youth factors for hope, optimism, and success? Women \& Criminal Justice, 19, 251-266.

Braun, V. Clarke, V. (2006). Using thematic analysis in psychology. Qualitative Research in Psychology, 3, 77-101.

Callon, M. Law, J. (1995). Agency and The Hybrid Collectif. South Atlantic Quarterly, 94, 481-507.

Campbell-Sill, L., Cohan, S. L., \& Stein, M. B. (2006). Relation- ship of resilience to personality, coping and psychiatric symptoms in young adults. Behaviour Research and Therapy, 44, 585-599.

Castañada, T., \& del Pilar Grazioso, M. (2017). Resilience in Guatemala: contextual overview with future perspectives. In G. Rich, \& S. Sirikantraporn, (Eds.), Human Strengths and Resilience; (pp.59-73). Developmental, Cross-Cultural and International Perspectives NY: Lexington

Cicchetti, D \& Toth, S. (1998). The development of depression in children. American Psychologist 53, 221-241. 
Bartels, M., \& Hudziak, J. J. (2007). Genetically informative designs in the study of resilience in developmental psychopathology. Child and Adolescent Psychiatry Clinics of North America, 16, 323-340.

Burrell, J. (2010). In and out of rights: security, migration, and human rights talk in postwar Guatemala. Journal of Latin American and Caribbean Anthropology, 15, 90-115.

Chandler, D. \& Coaffee, J. (2016). The Routledge Handbook of International Resilience: London: Routledge.

Clauss-Ehlers, C. (2008). Sociocultural factors, resilience, and coping: Support for a culturally sensitive measure of resilience. Journal of Applied Developmental Psychology, 29, 197-212.

Dahlman, S., Backstrom, P., Bohlin, G., \& Frans, O. (2013). Cognitive abilities of street children: Low-SES Bolivian boys with and without experience of living in the street. Child Neuropsychology, 19, 540-556.

Donnon, T. \& Hammond, W. (2007). Understanding the relationships between resiliency and bullying in adolescence: An assessment of youth resiliency from five urban junior high schools. Child and Adolescent Psychiatric Clinics of North America, 16, 449472.

Duff, C. (2008). The drifting city: The role of affect and repair in the development of “Enabling Environments”. International Journal of Drug Policy 20, 202-208.

Evans, G. \& Kim, P. (2012). Childhood poverty, chronic stress, self-regulation, and coping. Child Development Perspectives, 7, 43-48

Friborg, O., Barlaug, D., Martinussen, M., Rosenvinge, J., \& Hjemdal, O. (2005). Resilience in relation to personality and intelligence. International Journal of Methods in Psychiatric Research., 14, 29-42. 
Gallagher, N., Gretebeck, K., Robinson, J., Torres, E., Murphy, S., \& Martyn, K. (2010). Neighborhood factors relevant for walking in older, urban, African American adults. Journal of Aging and Physical Activity, 18, 99-115.

Gibson-Graham, J. (2003). An Ethics of the Local. Rethinking Marxism 15, 49-74.

Ghazinour, M., Richter, J., \& Eisemann, M. (2003). Personality related to coping and social support among Iranian refugees in Sweden. Journal of Nervous and Mental Diseases, 191, 595-60.

Goldstein, D. (2016). Owners of the sidewalk: security and survival in the informal city. London: Duke University Press.

Greiffenhagen, C. \& Sharrock, W. (2008). School mathematics and its everyday other? Revisiting Lave's cognition in practice. Educational Studies in Mathematics, 69, 1-21.

Groot, S., \& Hodgetts, D., (2015). The infamy of begging: A case-based approach to street homelessness and radical commerce. Qualitative Research in Psychology, 12, 349-366.

Hernandez, M., Hong, L., Frias-Martinez, V., Whitby, A., \& Frias-Martinez, E. (2017). Estimating poverty using cell phone data evidence from Guatemala. World Bank Group, Policy research working paper, 7969, 1-23.

Hu, T., Zhang, D., \& Wang, J. (2015). A meta-analysis of the trait resilience and mental health. Personality and Individual Differences, 76, 18- 27.

Jackson, A., \& Mazzei, L. (2012). Thinking with theory in qualitative research. New York: Routledge.

Joanou, J. (2014). Tu sabes que somos de calle: The Roelf thirdspace in the construction of a street child identity. Journal of Contemporary Ethnography, 43, 601-623.

Kagan, C, Burton, M, Duckett, P, Lawthom, R \& Siddiquee, A 2011, Critical community Psychology, Wiley-Blackwell, West Sussex, UK. 
Karabanow, J. (2003). Creating a culture of hope: Lessons from street children agencies in Canada and Guatemala. International Social Work, 46, 369-386.

Karabanow, J., Gurman, E., \& Naylor, T. (2012). Street youth labour as an expression of survival and self-worth: voices from youth in Guatemala City. Critical Social Work, 13, 42-59.

Keenan, T, Evans, S., Crowley, K. (2016). An Introduction to Child Development, London: Sage Langdridge, D. \& Hagger-Johnson, G., (2013). Introduction to research methods and data analysis in psychology. Harlow: Pearson.

Lefebvre, H. (1971). The Production of Space. London: Blackwell.

Lee, T., Shek, D., \& Kwong, W. (2007). Chinese approaches to understanding and building resilience in at-risk populations. Child and Adolescent Psychiatric Clinics of North America, 16, 377-392.

Le Mèner, E., \& Oppenchaim, N. (2012). The temporary accommodation of homeless families in Ile-de-France: Between social emergency and immigration management. European Journal of Homelessness, 6, 83-103.

Levine, M., Perkins, D. D., \& Perkins, D. V. (2005). Principles of community psychology:

Perspectives and applications (3rd ed.). New York: Oxford University Press.

Liborio R, Ungar M. 2010. Children's perspectives on their economic activity as a pathway to resilience. Children and Society 24: 326-338.

Liebel, M. (2004). A will of their own: Cross cultural perspectives on working children. New York: Zed.

Literat, I. (2013). A Pencil for your thoughts: Participatory drawing as a visual research method with children and youth. International Journal of Qualitative Methods, 12, 8598. 
Lounsbury, D. Mitchell, S. (2009). Introduction to special issue on social ecological approaches to community health research and action. American Journal of Community Psychology, 44, 213-220.

Mizen, P, \& Ofosu-Kusi, Y, 2013, ‘A Talent for Living: Exploring Ghana’s 'New’ Urban Childhood', Children and Society, vol. 27, no.13-23.

Pink, S. (2009). Doing Sensory Ethnography. London: Sage.

Massey, S. (2013). Introducing impact validity. Journal of Social Issues. 69, 619-632.

Masten, A. S. (2001). Ordinary magic: Resilience processes in development. American Psychologist, 56, 227-238.

Masten, A. et al (2014) Academic Risk and Resilience in the Context of Homelessness, Child Development Perspectives. 8(4): 201-206.

Matthews, H. Limb, M., \& Taylor, M. (2000). The Street as thirdspace: Class, gender, and public space. In L. Holloway, \& G. Valentine, (Eds.), Children's Geographies: Playing, Living, Learning, (pp. 194-210). New York: Routledge.

Mikami, A. \& Hinshaw, S. (2006). Resilient adolescent adjustment among girls: Buffers of childhood peer rejection and attention-deficit/ hyperactivity disorder. Journal of Abnormal Child Psychology, 34, 825-839.

Mizen, P. Ofosu-Kusi, Y. (2013). A talent for living: Exploring Ghana’s ‘new’ urban childhood. Children and Society 27, 13-23.

Moles, K. 2008. A walk in the third space. Sociological Research Online, 13, 2-4.

Muñoz-Echeverri, I., Noreña-Herrera, C., Londoño, B., \& Rojas-Arbeláez, C. (2011).

Morbilidad atendida y conductas de riesgo de la niñez y adolescencia en situación de calle de Medellín. Revista de Salud Pública, 13, 207-218.

National Research Council. (2010). Student mobility: Exploring the impact of frequent moves on achievement: Summary of a workshop. Washington, DC: National Academies Press. 
Nix, R., Pinderhughes, E., Bierman, K., Maples, J., \& Conduct Problems Prevention Research Group. (2005). Decoupling the relation between risk factors for conduct problems and the receipt of intervention services: Participation across multiple components of a prevention program. American Journal of Community Psychology, 36, $307-325$.

Oldfield, J, Stevenson, A., Ortiz E., \& Haley, B. (2018). Promoting or suppressing resilience to mental health outcomes in at risk young people: The role of parental and peer attachment and school connectedness. Journal of Adolescence, 64, 13-22.

Pacherres, M. (2003). Infancia y trabajo: Niñas y niños que trabajan en una zona urbana de Lima. In M, Ifejant, (Ed.), Infancia y adolescencia en América Latina Lima, Peru: Instituto de Formación Para Educadores de Jóvenes y Niños Trabadores de América Latina y el Caribe. (pp. 173-188).

Padgett,D., Smith, B., Derejko, K., Henwood, B., \& Tiderington, E. (2013). A Picture Is Worth ... ? Photo elicitation interviewing with formerly homeless adults. Qualitative Health Research, 23, 1435-1444.

Papaloukas, P, Quincey, K, \& Williamson, I, (2017). Venturing into the visual voice: combining photos and interviews in phenomenological inquiry around marginalisation and chronic illness. Qualitative Research in Psychology, 14, 415-441.

Parks, R. Stevens, R. \& Spence, S. (2007). A systematic review of cognition in homeless children and adolescents. Journal of the Royal Society of Medicine, 100, 46-50.

Pauwels, L, (2015). Participatory visual research revisited: a critical-constructive assessment of epistemological, methodological and social activist tenets, Ethnography, 17, 95117.

Pink, S. (2009). Doing Sensory Ethnography. London: Sage

Pluck, G. (2015). The 'street children' of Latin America. The Psychologist, 28, 20-3. 
Prout, A. (2002). Participation, policy, and the changing conditions of childhood. In C. Hallet \& A . Prout (Eds.), Hearing the voices of children (pp. 11-15). New York: Routledge/Falmer.

Power, N Norman, M, \& Dupré, K. (2014). Rural youth and emotional geographies: how photovoice and words-alone methods tell different stories of place. Journal of Youth Studies, 17, 1114-1129.

Romeo, R. D., \& McEwen, B. S. (2006). Stress and the adolescent brain. In B. M. Lester, A. S. Masten, \& B. McEwen (Eds.), Resilience in children (pp. 202-214). Boston, MA: Blackwell.

Ryan, C., Russell, S., Huebner, D., Diaz, R., \& Sanchez, J. (2010). Family acceptance in adolescence and the health of LGBT young adults. Journal of Child and Adolescent Psychiatric Nursing. 23, 205-213.

Saxe, G. (1988). The mathematics of street child vendors. Child Development, 59, 1415-1425.

Sloan, T. (2002). Psicologia de la liberacion: Ignacio Martín-Baró. Inter-American Journal of Psychology, 36, 353-357.

Shinn, M., \& Greer, A. (2011). The European Consensus Conference on HomelessnessKudos, and some cautions, to Europe. European Journal of Homelessness, 5, 183-190

Soja, E. (1996). Thirdspace: Journey to Los Angeles and other real and imagined places. Malden, MA: Blackwell.

Spradley, J. (1979). The ethnographic interview. California: Wadsworth Publishing. Schlaefer, K. (2005). Voices from the shadows. Berkeley, CA: University of California Stevenson, A. (2014). We came here to remember: Using participatory sensory ethnography to explore memory as emplaced, embodied practice. Qualitative Research in Psychology. 11, 335-349. 
Theron, L. \& Engelbrecht, P. (2012). Caring teachers: Teacher- youth transactions to promote resilience. In M. Ungar (Ed.), The social ecology of resilience: A bandbook of theory and practice (pp.265-280). New York, NY: Springer.

Tobin K, Murphy J. (2013) Addressing the challenges of child and family

homelessness. Journal of Applied Research on Children, 4 (9)p.2011-2663.

Thomas de Benitez, S. (2007). State of the world's street children: Violence. London: Consortium for Street Children.

Thrift, N. (2005). But malice aforethought: Cities and the history of hatred. Transactions of the Institute of British Geographers, 30, 133-150.

Tough, P. (2009). Whatever it takes: Geoffrey Canada's quest to change Harlem and America. New York, NY: Houghton Mifflin Harcourt: First Mariner Books

Ungar, M. (2011). The social ecology of resilience: addressing contextual and cultural ambiguity of a nascent construct. American Journal of Orthopsychiatry 81, 1-17.

Ungar, M. (2012). Researching and theorizing resilience across cultures and contexts Preventive Medicine, 55, 387-389.

Ungar, M., Ghazinour, M., \& Richter, J. (2013). What is resilience within the social ecology of human development? American Journal Orthopsychiatry, 81, 1-17.

Ungar, M. (2015). Practitioner review: diagnosing childhood resilience - a systematic approach to the diagnosis of adaption in adverse social and physical ecologies. Journal of child Psychology and Psychiatry, 56, 4-17.

U.S. Aid. (2016). Guatemala Project Brief: Education. US Aid Guatemala, 1-2.

Zautra, A., Hall, J. \& Murray, K. (2010). Resilience: A new definition of health for people and communities. In J. Reich, A. Zautra, \& J. Hall (Eds.), Handbook of Adult Resilience (pp. 3-34). New York, NY: Guilford. 